\title{
The Sound of Programming
}

\section{In the early days of digital computing; it was not uncommon to find a radio receiver tuned to a particular frequency (I don't recall which one, sigh) so that the RF emitted by the computer}

could be picked up and played through the radio. You could tell when a program went into a loop and sometimes you could tell roughly where a computation had reached by the sounds coming from the radio monitor. Fastforward to the $21^{\text {st }}$ century and we are seeking a different kind of sound: the sound of programming.

Bootstrap World ${ }^{\text {a }}$ has developed online courses in programming, among other subjects, but what makes Bootstrap World so memorable for me is that the team has focused heavily on accessibility. The programming environment is extremely friendly to screen readers so that a blind programmer can navigate easily through complex programs using keyboard navigation coupled with oral descriptions/renderings of the program text and structure. ${ }^{\mathrm{b}}$ A recent visit from Emmanuel Schanzer, founder of Bootstrap World, reinforced my positive impression of the group and Schanzer's enthusiasm and commitment to education for everyone.

As I watched and listened, Schanzer began writing a program using a visual language that is coupled with a concomitant audible description of where the programmer is in the program. The programming language encourages clean programming structure and that makes it possible for audible navigation without becoming hopelessly lost. Among the many

\footnotetext{
a www.bootstrapworld.org

b http://www.bootstrapworld.org/blog/ accessibility/User-Interface-REPL.shtml
}

things I learned from this exercise is the ability of blind people to listen to speech that seems three to five times faster than normal speech. It reminded me of the radio commercials that draw you in with various audible gimmicks, pitch you, and then, at the end, a chipmunk voice announces all kinds of terms and conditions for accepting the offer. The rapid-fire rendering is essential for any timely navigation of the program or confirmation of changes to it.

My thoughts were drawn to the inverse situation in which the programmer might be able to narrate the program text and have the computer absorb and orally respond or confirm its understanding of the programmer's intent. At some point, one fantasizes a dialog with an intelligent agent that makes comments about bugs and mistakes ("You screwed up again, Einstein! That's a buffer overflow!"). Whether we ever get to that point or not, the idea that one could get semantic or cognitive help from a sophisticated computer program to help write more sophisticated computer programs is very attractive. The same structuring that makes it easier to navigate audibly might also make the program more easily analyzed for flaws.

What seems more important about the work at Bootstrap World is the potential to provide students closer to STEM learning with tools that move at the same pace at which the students can move. The notion of self-paced learning has a great deal of attraction.
People learn at different speeds and use different methods to reinforce what they are learning. The Bootstrap World program is designed for this kind of adaptability and flexibility. At a time when science and technology need an increasing population of STEM-educated workers, the traditional methods of four-year college and perhaps graduate study may not be optimal. With longer lives and longer careers, it is likely we will all need to return to school or at least to enter a learning phase more than once in our careers. Adaptable and convenient online learning is sure to be a part of $21^{\text {st }}$-century careers. It is no longer feasible or even sensible to try to pack all one needs for a lifetime of work into a few years at the beginning of our lives.

One final note: I am persuaded more than ever that we learn best by trying to do something, perhaps failing, getting some guidance, and trying again. This seems like a form of just in time learning not unlike what I experience when I write these columns. I get stuck somewhere (usually more than once) and turn to Google or YouTube to find out how or what from these media. That sounds like a wave of the future to me.

Vinton G. Cerf is vice president and Chief Internet Evangelist at Google. He served as ACM president from 2012-2014.

Copyright held by owner/author. 